\title{
Constructing a Scale of Attitudes toward School Science Using the G eneral G raded Unfolding Model
}

\author{
Taghreed Hijazi* Zaid Bani Ata \\ Yarmouk University, Jordan
}

Submitted: $23 / 5 / 2012$

Revised: 6/3/2013

Accepted: 31/5/2013

The present study aimed at constructing an attitude scale toward school science using the generalized graded unfolding model (GGUM). A 47-item scale ( 24 positive, 23 negative) with 4-point response format was used to measure attitudes toward science among $9^{\text {th }}(n=424)$ and $10^{\text {th }}$ $(n=420)$ grade students in 38 sections distributed randomly over 22 schools in Irbid district. Respondents selected one of four options to represent their level of agreement with each item. The findings support the hypothesis that the data form a single unidimensional unfolding model. Furthermore, the findings showed that the GGUM didn't fit the data of 7 items, leaving the final scale with 40 items, where accurate estimates of these item parameters were derived and the GGUM was appropriate. Cronbach's al pha for the internal consistency, and the test retest reliability coefficients of the final scale were 0.932 and 0.875 , respectively.

Keywords: unfolding model, attitude scale, attitude toward science, Irbid school district.

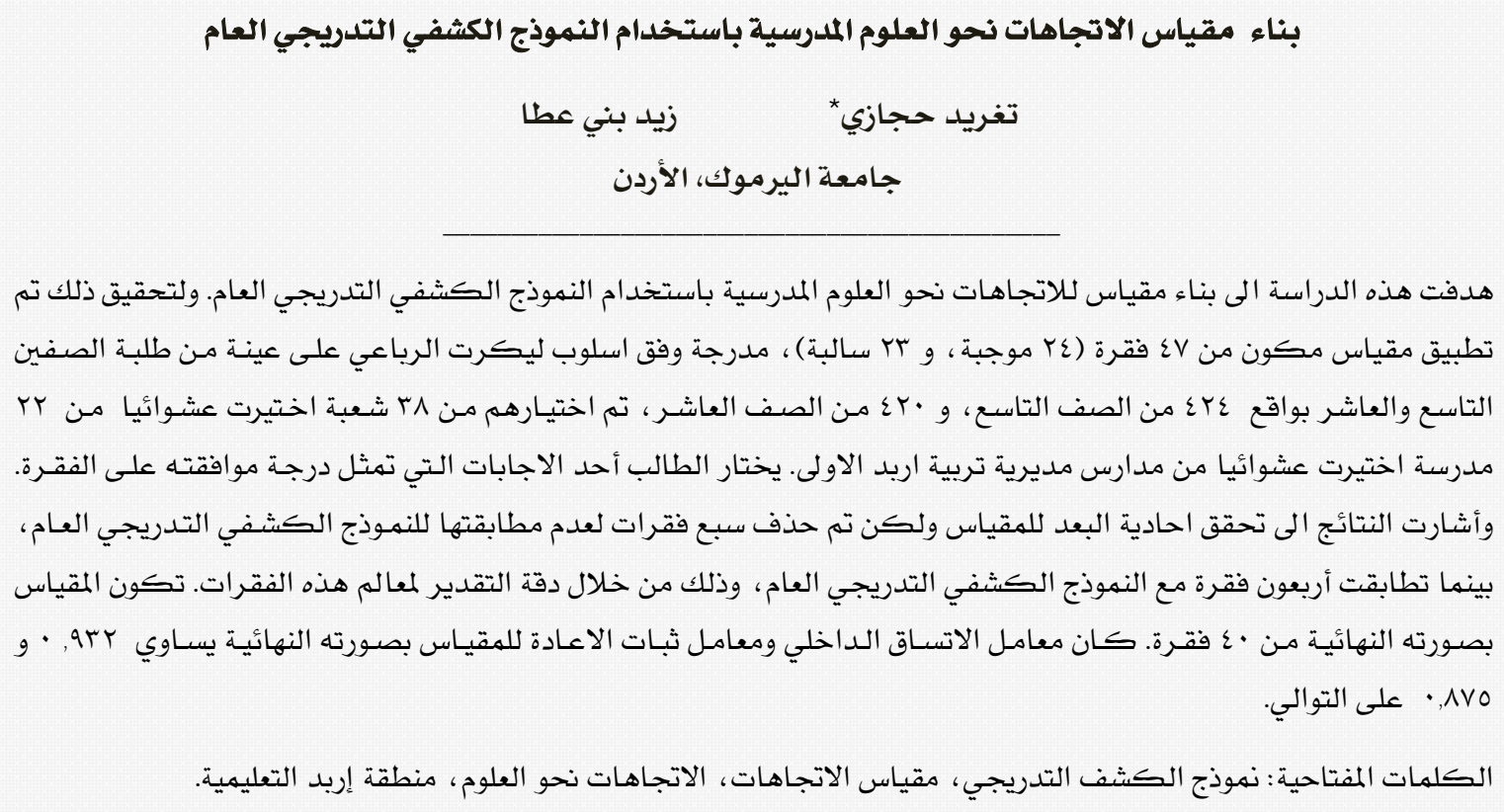

*taghreedah@yahoo.com 
Understanding students' attitudes is important in supporting their achievement and interest toward a particular discipline; so identification and influence of attitudes became an essential part of educational research (Prokop, Tuncer, \& Chuda, 2007). There is much interest in science subjects in high school and students attitudes toward those subjects because students' attitudes toward science affect their achievement in science. Many Studies re ported a positive correlation between science attitude and science achievement (Morse and Morse, 1995; Schibeci and Riley, 1986; Simpson and Oliver, 1990). Such attitudes received attention in science education research, and it became one of the most important goals of the curriculum to develop an appositive attitude toward science (Koballa and Crawley, 1985; Laforgia, 1988, Osborne, Simon, \& Collins, 2003).

To measure changes over time in scientific attitudes, valid, and precise scales are needed. There are two main response processes for constructing social psychological scales: cumulative and unfolding processes. They relate the responses to locations of persons and items on the latent trait continuum. In the cumulative process, the greater the location of the person relative to the location of the item on the continuum, the greater the probability of a positive response. This process is based on the dominance relation, and defines item traceline that is monotonically increasing. While in the unfolding process, the closer the location of the person to the location of the item on the continuum, the greater the probability of a positive response. Thus, it is based on the proximity relation, and defines single-peaked shape where probability of choosing an item increases with decreasing distance between person and item (Andrich, 1988, 1993; Hoijtind, 1990, 1991). Unfolding model is considered in this study.

Many researchers have argued that binary or graded agree-disagree responses result from an ideal point process in which a person endorses an item to the extent that it matches his/ her opinion (Andrich, 1996; Roberts, Laughlin, \& wedell, 1999; \& Van Schuur and Kiers, 1994). This argument implies that the unfolding model is more appropriate for the agree-disagree data than the cumulative model (Roberts, 1995; Roberts, Donoghue, \& Laughlin, 2000, Roberts and Laughlin, 1996).
The generalized graded unfolding model (GGUM) is an item response theory (IRT) model that is commonly used by psychologists. It comprises a collection of modeling techniques that offer many advantages over classical theory. By considering the correlation among the item responses, IRT extracts more information from the data, more information can be gained about the relationship between the items on the test and the construct being measured (Embretson, 1996). It specifies the relationship between a person's observed responses to a set of items and the unobserved latent trait that is being measured by the item set. It also implements Single-Peaked, nonmonotonic probability functions, and allows for binary or graded agree-disagree responses (Roberts, 2001; Roberts et al., 2000; \& Roberts, Lin, \& Laughlin, 2001). Furthermore, if a parametric unfolding model is used, and adequately fits the data, then the item parameters will be sample free and the person parameters will be item invariant (Hambleton, Swaminathan, \& Rogers,1991; Hoijtink,1990).

The GGUM allows for differential response category use across items, it also allows variable levels of discrimination among items, and has the properties of sample invariant interpretation of item parameters, item invariant interpretation of person parameters (Roberts, 2001; Roberts, 2003; Roberts et al., 2000; Roberts et al., 2001).

For attitude measurement in the GGUM, binary or graded agree-disagree responses to attitude items are often collected, where a person may respond in a given response category for either of two reasons. For example, a person might strongly disagree with an attitude item because its content is either too negative or too positive relative to his/ her opinion. If the item content is too negative, the person "disagree from above the item" because the person is located far above the item's location on the attitude continuum. If the item content is too positive, the person "disagree from be low the item" because the person is located far below the item's location. (Roberts and Laughlin, 1996; Roberts et al., 2000). The GGUM represented by the following equation below (Roberts et al., 2001): 


$$
p\left(Z_{i}=z \mid \theta_{j}\right)=\frac{\exp \left\{\alpha_{i}\left[z\left(\theta_{j}-\delta_{i}\right)-\sum_{k=0}^{z} \tau_{i k}\right]\right\}+\exp \left\{\alpha_{i}\left[(M-z)\left(\theta_{j}-\delta_{i}\right)-\sum_{k=0}^{z} \tau_{i k}\right]\right\}}{\sum_{w=0}^{c}\left\{\exp \left\{\alpha_{i}\left[w\left(\theta_{j}-\delta_{i}\right)-\sum_{k=0}^{w} \tau_{i k}\right]\right\}+\exp \left\{\alpha_{i}\left[(M-w)\left(\theta_{j}-\delta_{i}\right)-\sum_{k=0}^{w} \tau_{i k}\right]\right\}\right\}}
$$

Where

$Z_{i}=$ is an observable response to attitude statement $\mathrm{i}$;

$\mathrm{z}=0,1,2, \ldots . . \mathrm{C}$.

$\theta_{j}$ is the location of person $\mathrm{j}$ on the attitude continuum;

$\delta_{l}$ is the location of attitude statement $i$ on the attitude continumm;

$\alpha_{i}$ is the discrimination of attitude statement $i$;

$\tau_{i k}$ is the location of the $k^{\prime}$ th subjective response category (SRC) threshold on the attitude continuum relative to the location of the ith item; and

$M$ is the number of SRCs minus 1.

The item response function is single-peaked, and symmetric about $\theta_{\varphi}-\delta_{\mathrm{I}}=0$, by computing the expected value of an observable response for various values of $\theta_{\varphi}-\delta_{1}$ using the probability function given in the equation (Roberts, et al., 2000; Roberts et al., 2001).

Many studies have used different versions of GGUM for different purposes. Roberts \& Laughlin (1996) used the graded unfolding model (GUM) to analyze the responses of 245 respondents to Thurston's attitude toward capital punishment scale of 24 items. The results showed that 17 items fit the model well, with a gap between the estimated locations due to the lack of items in the initial pool that reflect the intermediate opinions. Roberts, et al. (2001), on the other hand used the GGUM 2000 in order to minimize the number of items required to produce accurate estimates of persons' locations where 50 items were used to measure attitudes toward abortion among 750 respondents. The results showed that 47 items fit the model, and the item discrimination coefficients were within reasonable range (.41-2.15). Additionally, the results indicated that the scale can be used to measure attitude trait accurately at middle trait attitude score.

Zampetakis (2010) used the GUM to model binary responses, and a Greek version of the Gough's Creative Personality Scale (CPS) of 30 items was administered to 288 engineering students. The results indicated unidimensionality of the CPS construct, where all of 30 items fit the model, and that the scale can be used to measure attitude trait accurately at lower to middle scores of the trait level scores.

Roberts, Donoghue, \& Laughlin (1999) used the GGUM 1998 to investigate the conditions under which item parameter estimation accuracy increases or decreases, based on a recovery simulation in which the effects of sample size, item location, degree of item discrimination, and extremity of subjective category thresholds were varied. The findings demonstrated that with 750 or more respondents, sample size has no effect on all but the estimation of subjective response category thresholds. The true extremity of both item location and item discrimination affected the estimation of these parameters themselves, and also affected the estimation of other item parameters in the model. However, these effects were modest and had little impact on the estimation of the corresponding item response functions. Findings suggest that marginal maximum likelihood estimates of item parameters will provide accurate results across a variety of item parameter configurations when the sample size is at or above the recommended levels.

In a study by Wang and Liu (2011) aimed to develop two methods of item selection in computerized classification testing using the GGUM, the current estimate/ ability confidence interval method and the cut-off score/ sequential probability ratio test method were used. They evaluated the accuracy and efficiency of both methods in classification through simulation. The results indicated that both methods were very accurateand efficient. The more points each item had and the fewer the classification categories, the more accurate and efficient the classification would be. However, the latter method may yield a very low accuracy in dichotomous items with a short maximum test length. Thus, if it is to be used to classify examinees with dichotomous items, the maximum text length should be increased.

Unfortunately, there is a lack of using (GGUM) in constructing attitude scales toward school science in Jordan. This study aimed at constructing a reasonably accurate attitude scale toward school science using the GGUM. Educators in Jordan may benefit from the scale of this study in practical situations of science attitude measurement. In addition, to the best of the researchers' knowledge, this is the first study in Jordan that constructed an attitude scale toward school science according 
to the GGUM. Based on Hambleton, Swaminathan, \& Rogers (1991) and Hoijtink (1990), if the model fits the data of the present study, the item parameters will be sample free and the person parameters will be item invariant. Moreover the model can be useful to applied attitude research.

\section{Operational definitions}

Person Parameter: The location of person $\mathrm{j}$ on the attitude toward school science continuum. Item Parameter: The location of attitude statement $\mathrm{i}$ on the attitude toward school science continuum.

Attitude toward School Science: The score of 9 'th and $10^{\prime}$ th grade students in Irbid district on the attitude scale toward school science constructed in the present study. The Generalized Graded Unfolding Model (GGUM): An item response theory model that implements a singlepeaked response function, and allows for either binary or graded data.

\section{Purpose of research}

This study aimed at constructing an attitude scale toward school science using the GGUM. Specifically, the study will address the following questions:

1. How well the data fit the GGUM?

2. What are GGUM item parameter estimates derived from using the marginal maximum likelihood?

\section{METHOD}

\section{Sample}

Data were collected from fairly similar numbers of $9^{\text {th }} \quad(n=424)$, and $10^{\text {th }} \quad(n=420)$ grade students in 38 section distributed over randomly selected 22 schools in Irbid district.

\section{Instrument}

A 50 -item ( 25 positive, 25 negative) scale with 4-point response format was prepared according to the related research (Cheung, 2009; George, 2006; Germann, 1988; Prokop et al., 2007; Salta and Tzougraki, 2004; \& Siegel and Ranney, 2003) to represent the full range of attitude toward school science.

The scale was independently revised by three experts in measurement and evaluation, four experts in psychology, and three science teachers in order to maintain validity. The revision led to the omission of three items because of repetition, and 47 items retained in the final form of the scale.

Students selected one of four options to represent their level of agreement with each of the 47 items. Both positive and negative items were scored from 1 to 4, from "strongly disagree" to "Strongly agree".

\section{Item bank development}

Unidimesionality: Responses of 47 items (24 positive, and 23 negative were scored in the same order with 4 - point response format, where 1 = strongly disagree, $2=$ disagree, $3=$ agree, 4 = strongly agree, without reversing the score order of the negative items) were analyzed using the statistical package for social sciences program (SPSS) for principal components analysis to examine which items were least likely to conform to the unidimensionality assumption of the GGUM. Table 1 shows the factors, eigenvalues, variance, and cumulative variance.

Table 1

Total Variance Explained

\begin{tabular}{ccccccc}
\hline \multicolumn{2}{c}{ Extraction Sums of Squared Loadings } & \multicolumn{3}{c}{ Initial Eigenvalues } \\
Cumulative \% & \% of Variance & Total & Cumulative \% & \% of Variance & Total & Component \\
\hline 28.202 & 28.202 & 13.255 & 28.202 & 28.202 & 13.255 & 1 \\
34.677 & 6.475 & 3.043 & 34.677 & 6.475 & 3.043 & 2 \\
39.472 & 4.795 & 2.253 & 39.472 & 4.795 & 2.253 & 3 \\
43.107 & 3.636 & 1.709 & 43.107 & 3.636 & 1.709 & 4 \\
46.527 & 3.420 & 1.607 & 46.527 & 3.420 & 1.607 & 5 \\
49.471 & 2.943 & 1.383 & 49.471 & 2.943 & 1.383 & 6 \\
52.375 & 2.904 & 1.365 & 52.375 & 2.904 & 1.365 & 7 \\
55.127 & 2.753 & 1.294 & 55.127 & 2.753 & 1.294 & 8 \\
57.806 & 2.679 & 1.259 & 57.806 & 2.679 & 1.259 & 9 \\
60.227 & 2.421 & 1.138 & 60.227 & 2.421 & 1.138 & 10 \\
62.618 & 2.391 & 1.124 & 62.618 & 2.391 & 1.124 & 11 \\
64.977 & 2.359 & 1.109 & 64.977 & 2.359 & 1.109 & 12 \\
67.192 & 2.215 & 1.041 & 67.192 & 2.215 & 1.041 & 13 \\
69.332 & 2.140 & 1.006 & 69.332 & 2.140 & 1.006 & 14 \\
\hline
\end{tabular}


As seen in Table 1 analysis extracts 14 factors, all with an eigenvalue greater than 1 . The first factor explains $28.20 \%$ of the variance it is nearly 4.5 times larger than the second factor 6.48. The eigenvalue of the first factor is 13.26 , and the second factor is 3.04. Based on Hattie (1984) if the proportion of the eigenvalue of the first factor to the eigenvalue of the second factor is greater than 2 this is an indicator of the unidimensioality assumption for the GGUM held for the data use in the study. Furthermore the scree plot (eigenvalues versus component number) is shown in figure 1.

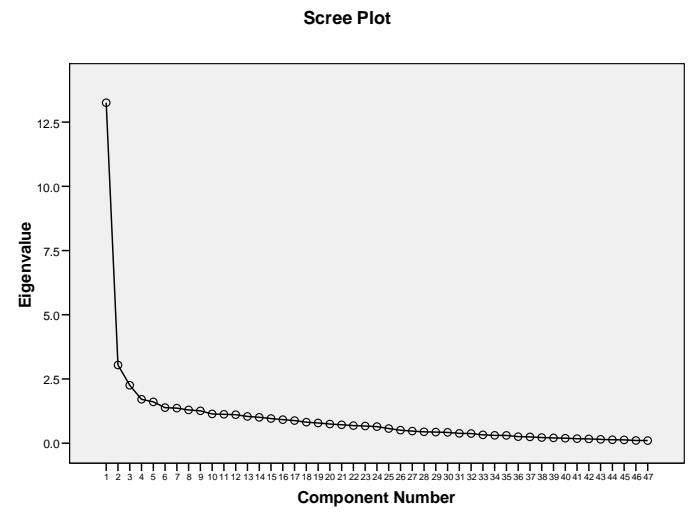

Fig. 1: Scree Plot U sed to A ssess Unidimensionality Assumption

The results shown in Figure 1 indicate the dominance of the first factor, there is no cutoff between adjacent higher-order factors. Furthermore, the test is essentially unidimensional.

\section{Results related to the first question: global model fit}

In order to assess the extent to how much the IRT model assumptions are valid for the given data and how well the data fit the IRT model, the whole data set were analyzed using the GGUM (Roberts, 2004), where all of the 47 items were scored from 1 to 4, from "strongly disagree" to "Strongly agree", respectively without reversing the score order of the negative items. Differences between each person's attitude estimate and each estimated item location $\left(\hat{\theta}_{j}-\widehat{\delta}_{i}\right)$ were calculated, sorted and divided into 100 homogeneous groups of approximately equal size. The average observed and expected responses based on the GGUM were calculated for each group. The average expected values and average observed scores are then plotted as a function of the mean $\widehat{\theta}_{j}-\widehat{\delta}_{i}$ value within each homogeneous group as shown in figure 2 .

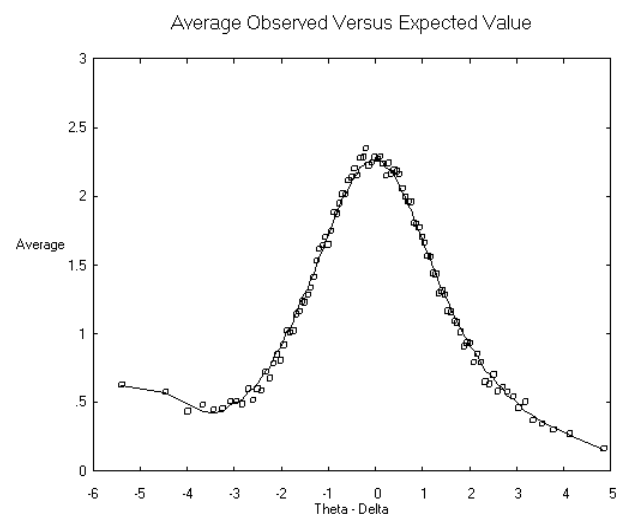

Fig. 2: A verage $O$ bserved $V$ ersus Expected $V$ alue

It is clear from Figure 2 that the average expected (solid line) and the average observed (squares) responses increased as the mean difference between person and item locations approached zero, indicating that the model fit the data.

\section{Results related to the second question:}

\section{Parameter estimation}

The GGUM model uses expected a posteriori (EAP) for estimating person parameters (Roberts, 2004). Person-level fit was assessed using $\chi^{2}$ statistics. Analysis led to removing 52 persons. Table 2 presents the misfit person parameter estimates.

Table 2 shows that the misfit person parameters $\theta_{\mathrm{j}}$ ranged from (-2.89 to 2.90), and $\square^{2}$ was $<0.01$ at $\alpha=0.01$ for all of misfit persons, with significant differences between their expected and observed responses.

GGUM item parameters were estimated using marginal maximum likelihood, and $\mathrm{G}^{2}$ statistic values were estimated to assess the item- level fit. Table 3 shows the item parameters. 
Table 2

G G U M Person Parameter for M isfit Persons

\begin{tabular}{|c|c|c|c|c|}
\hline Person Number & $\theta_{i}$ & $\gamma^{2}$ & DF* & $P$ \\
\hline 407 & -2.89 & 88.09 & 46 & 0.003 \\
\hline 216 & -2.39 & 133.8 & 46 & 0.000 \\
\hline 7 & -2.37 & 87.50 & 46 & 0.001 \\
\hline 3 & -2.10 & 91.56 & 46 & 0.001 \\
\hline 341 & -2.06 & 103.6 & 46 & 0.001 \\
\hline 4 & -2.04 & 132.2 & 46 & 0.000 \\
\hline 9 & -2.04 & 132.0 & 46 & 0.007 \\
\hline 207 & -2.00 & 110.0 & 46 & 0.000 \\
\hline 223 & -1.58 & 118.4 & 46 & 0.007 \\
\hline 12 & -1.24 & 91.22 & 46 & 0.000 \\
\hline 411 & -1.23 & 90.00 & 46 & 0.008 \\
\hline 5 & -1.21 & 92.13 & 46 & 0.004 \\
\hline 99 & -1.17 & 122.3 & 46 & 0.004 \\
\hline 232 & -1.07 & 91.14 & 46 & 0.002 \\
\hline 142 & -1.04 & 89.76 & 46 & 0.000 \\
\hline 199 & -0.90 & 94.00 & 46 & 0.003 \\
\hline 8 & -0.89 & 213.2 & 46 & 0.001 \\
\hline 469 & -0.89 & 102.2 & 46 & 0.001 \\
\hline 204 & -0.88 & 100.0 & 46 & 0.000 \\
\hline 200 & -0.87 & 89.01 & 46 & 0.000 \\
\hline 384 & -0.87 & 100.4 & 46 & 0.005 \\
\hline 205 & -0.76 & 93.09 & 46 & 0.000 \\
\hline 202 & -0.56 & 106.1 & 46 & 0.007 \\
\hline 6 & -0.50 & 134.4 & 46 & 0.000 \\
\hline 258 & -0.49 & 88.54 & 46 & 0.003 \\
\hline 215 & -0.44 & 109.8 & 46 & 0.002 \\
\hline 403 & -0.43 & 112.1 & 46 & 0.003 \\
\hline 1 & -0.26 & 85.31 & 46 & 0.000 \\
\hline 208 & 0.09 & 121.4 & 46 & 0.001 \\
\hline 11 & 0.14 & 86.90 & 46 & 0.000 \\
\hline 206 & 0.43 & 87.82 & 46 & 0.000 \\
\hline 266 & 0.56 & 88.22 & 46 & 0.008 \\
\hline 203 & 0.76 & 152.5 & 46 & 0.000 \\
\hline 361 & 0.89 & 87.31 & 46 & 0.006 \\
\hline 209 & 1.01 & 88.69 & 46 & 0.004 \\
\hline 2 & 1.14 & 111.9 & 46 & 0.000 \\
\hline 211 & 1.18 & 98.78 & 46 & 0.005 \\
\hline 418 & 1.18 & 93.09 & 46 & 0.004 \\
\hline 210 & 1.19 & 130.2 & 46 & 0.001 \\
\hline 10 & 1.2 & 95.00 & 46 & 0.000 \\
\hline 193 & 1.73 & 101.0 & 46 & 0.003 \\
\hline 212 & 1.98 & 148.0 & 46 & 0.001 \\
\hline 399 & 1.99 & 89.44 & 46 & 0.005 \\
\hline 426 & 1.99 & 87.06 & 46 & 0.003 \\
\hline 345 & 2.00 & 94.03 & 46 & 0.006 \\
\hline 349 & 2.02 & 148.7 & 46 & 0.009 \\
\hline 351 & 2.06 & 93.33 & 46 & 0.001 \\
\hline 404 & 2.12 & 128.3 & 46 & 0.001 \\
\hline 191 & 2.15 & 87.32 & 46 & 0.007 \\
\hline 286 & 2.59 & 86.87 & 46 & 0.004 \\
\hline 169 & 2.87 & 122.2 & 46 & 0.002 \\
\hline 287 & 2.90 & 94.04 & 46 & 0.004 \\
\hline
\end{tabular}


Table 3

G G UM Item Parameter Estimates (D erived from M arginal Maximum Likelihood Estimation) for 47 Attitude Items Toward Science

\begin{tabular}{|c|c|c|c|c|c|c|c|c|c|c|c|}
\hline & Item & $\delta \mathrm{i}$ & $\alpha_{\mathrm{i}}$ & $\tau_{\mathrm{i} 1}$ & $\tau_{12}$ & $\tau_{i 3}$ & $\tau_{\mathrm{i} 4}$ & SE & $\mathrm{G}^{2}$ & DF* & $P$ \\
\hline 20 & I dislike a career as a scientist. & -3.51 & 0.85 & 0.00 & -2.61 & -1.94 & -1.62 & 0.11 & 18.19 & 18 & 0.440 \\
\hline 43 & $\begin{array}{l}\text { Science subjects are not important in } \\
\text { comparison with other subjects. }\end{array}$ & -3.42 & 0.81 & 0.00 & -2.55 & -1.41 & 1.52 & 0.56 & 14.97 & 18 & 0.661 \\
\hline 41 & $\begin{array}{l}\text { I see that science subjects, present limited } \\
\text { information for a person. }\end{array}$ & -2.60 & 0.70 & 0.00 & -2.80 & -1.72 & 0.14 & 0.19 & 21.13 & 24 & 0.630 \\
\hline 19 & $\begin{array}{l}\text { I feel uncomfortable during study of } \\
\text { science subjects. }\end{array}$ & -2.39 & 0.74 & 0.00 & -2.21 & -1.70 & 0.07 & 0.28 & 15.44 & 24 & 0.913 \\
\hline 18 & $\begin{array}{l}\text { I feel my desire toward science subjects } \\
\text { decreases by time. }\end{array}$ & -2.25 & 0.81 & 0.00 & -1.88 & -1.64 & 0.08 & 0.15 & 31.29 & 24 & 0.154 \\
\hline 40 & Science subjects are repulsive. & -2.11 & 0.85 & 0.00 & -1.75 & -0.90 & -0.02 & 0.12 & 19.56 & 21 & 0.550 \\
\hline 36 & $\begin{array}{l}\text { I feel uncomfortable during study of } \\
\text { scientific subjects. }\end{array}$ & -1.96 & 0.66 & 0.00 & -1.78 & -1.72 & 0.02 & 0.08 & 26.36 & 27 & 0.003 \\
\hline 16 & I feel nervous in science lessons. & -1.77 & 1.36 & 0.00 & -1.82 & -1.07 & 0.04 & 0.15 & 13.97 & 15 & 0.532 \\
\hline 37 & $\begin{array}{l}\text { My studying of science subjects makes } \\
\text { me feel I'm doing significant thing. }\end{array}$ & -1.70 & 1.35 & 0.00 & -1.92 & -0.91 & -0.37 & 0.04 & 21.07 & 15 & 0.130 \\
\hline 13 & $\begin{array}{l}\text { Public money spent on science could have } \\
\text { been used more wisely for other purpos- } \\
\text { es. }\end{array}$ & -1.69 & 0.91 & 0.00 & -1.84 & -1.43 & -0.37 & 0.17 & 11.41 & 24 & 0.990 \\
\hline 12 & $\begin{array}{l}\text { Participation in scientific clubs is a waste } \\
\text { of time. }\end{array}$ & -1.61 & 0.97 & 0.00 & -2.22 & -1.44 & -0.50 & 0.14 & 13.75 & 24 & 0.951 \\
\hline 44 & $\begin{array}{l}\text { I feel studying science subjects is a waste } \\
\text { of time. }\end{array}$ & -1.54 & 0.79 & 0.00 & -1.32 & -1.24 & 0.44 & 0.16 & 31.37 & 24 & 0.141 \\
\hline 32 & $\begin{array}{l}\text { Science subjects provide me information } \\
\text { that is not known to the average person. }\end{array}$ & -1.40 & 1.09 & 0.00 & -2.20 & -1.19 & -0.36 & 0.09 & 25.94 & 24 & 0.362 \\
\hline 8 & $\begin{array}{l}\text { Knowledge of science helps in protecting } \\
\text { environment. }\end{array}$ & -1.3 & 0.97 & 0.00 & -2.04 & -1.47 & -.09 & 0.19 & 55.07 & 27 & 0.001 \\
\hline 31 & I lose attention in science lessons. & -1.21 & 0.95 & 0.00 & -1.55 & -1.08 & -0.07 & 0.13 & 25.73 & 27 & 0.534 \\
\hline 7 & $\begin{array}{l}\text { I dislike watching scientific programs on } \\
\text { T.V. }\end{array}$ & -1.12 & 0.93 & 0.00 & -2.24 & -1.48 & -0.27 & 0.13 & 19.14 & 27 & 0.865 \\
\hline 29 & I enjoy in studying science subjects. & -0.94 & 0.76 & 0.00 & -2.26 & -0.94 & -0.22 & 0.15 & 26.69 & 30 & 0.640 \\
\hline 6 & $\begin{array}{l}\text { I hate that my success in the future de- } \\
\text { pends on learning science subjects. }\end{array}$ & -0.81 & 0.72 & 0.00 & -1.72 & -1.39 & -0.13 & 0.12 & 23.15 & 30 & 0.809 \\
\hline 28 & $\begin{array}{l}\text { Disadvantages of science subjects domi- } \\
\text { nate its advantages. }\end{array}$ & -0.79 & 0.87 & 0.00 & -1.69 & -0.92 & -0.09 & 0.14 & 21.34 & 27 & 0.770 \\
\hline 23 & $\begin{array}{l}\text { Science subjects have nothing to do with } \\
\text { my life outside of school. }\end{array}$ & -0.72 & 0.66 & 0.00 & -1.19 & -0.69 & -0.23 & 0.08 & 50.08 & 30 & 0.022 \\
\hline 27 & $\begin{array}{l}\text { Science subjects are not important in the } \\
\text { evolution of human. }\end{array}$ & -0.62 & 0.64 & 0.00 & -1.65 & -1.25 & -0.48 & 0.09 & 24.47 & 30 & 0.751 \\
\hline 24 & $\begin{array}{l}\text { I feel that studying science subjects helps } \\
\text { refining my character. }\end{array}$ & -0.58 & 0.81 & 0.00 & -1.93 & -1.02 & -0.23 & 0.16 & 29.46 & 30 & 0.494 \\
\hline 2 & s are boring. & -0.55 & 0.89 & 0.00 & -1.93 & -1.27 & -0.18 & 0.06 & 28.26 & 30 & 0.557 \\
\hline 1 & $\begin{array}{l}\text { Science subjects are difficult to under- } \\
\text { stand. }\end{array}$ & -0.49 & 1.11 & 0.00 & -2.06 & -1.18 & -0.19 & 0.06 & 28.09 & 27 & 0.406 \\
\hline 30 & $\begin{array}{l}\text { I believe that science subjects are given } \\
\text { more attention than they deserve. }\end{array}$ & 0.35 & 1.02 & 0.00 & -2.30 & -1.29 & 0.68 & 0.13 & 30.15 & 27 & 0.308 \\
\hline 4 & $\begin{array}{l}\text { Science subjects are beneficial to every- } \\
\text { body. }\end{array}$ & 0.39 & 0.98 & 0.00 & -1.69 & -0.95 & -0.31 & 0.17 & 19.63 & 30 & 0.926 \\
\hline 5 & I wait for the science classes eagerly. & 0.41 & 0.77 & 0.00 & -1.49 & -0.89 & -0.07 & 0.09 & 18.98 & 30 & 0.940 \\
\hline 26 & $\begin{array}{l}\text { I wish to stay home when I have science } \\
\text { class. }\end{array}$ & 0.63 & 0.94 & 0.00 & -1.99 & -1.36 & -.054 & 0.28 & 25.28 & 30 & 0.009 \\
\hline 3 & $\begin{array}{l}\text { I like science subjects more than any other } \\
\text { subject. }\end{array}$ & 0.86 & 1.01 & 0.00 & -1.80 & -0.99 & -0.03 & 0.12 & 20.23 & 27 & 0.821 \\
\hline 25 & $\begin{array}{l}\text { I think that science subjects are the main } \\
\text { reason of technology development. }\end{array}$ & 0.99 & 1.22 & 0.00 & -1.78 & -1.25 & -0.23 & 0.20 & 31.56 & 24 & 0.138 \\
\hline 47 & $\begin{array}{l}\text { Science lessons will help prepare me for } \\
\text { major decisions in my future. }\end{array}$ & 1.03 & 0.90 & 0.00 & -2.05 & $0-.97$ & 0.43 & 0.08 & 10.98 & 27 & 0.997 \\
\hline 22 & $\begin{array}{l}\text { I like science subjects because they stimu- } \\
\text { late my thinking. }\end{array}$ & 1.12 & 1.01 & 0.00 & -2.20 & -1.22 & -0.46 & 0.04 & 13.10 & 24 & 0.007 \\
\hline 34 & I feel excited toward science subjects. & 1.13 & 0.63 & 0.00 & -1.87 & -1.34 & -0.45 & 0.07 & 30.90 & 30 & 0.421 \\
\hline 46 & $\begin{array}{l}\text { Interest in science subjects contribute to } \\
\text { the progress and advancement of society. }\end{array}$ & 1.25 & 0.70 & 0.00 & -1.78 & -0.91 & -0.16 & 0.09 & 36.71 & 27 & 0.101 \\
\hline 45 & $\begin{array}{l}\text { I wish school subjects are limited to } \\
\text { science subjects. }\end{array}$ & 1.25 & 0.99 & 0.00 & -1.97 & -0.81 & -0.19 & 0.18 & 23.00 & 27 & 0.685 \\
\hline 21 & $\begin{array}{l}\text { I gain from studying science subjects, } \\
\text { accuracy in work. }\end{array}$ & 1.40 & 0.71 & 0.00 & -1.62 & -1.86 & -0.20 & 0.15 & 44.71 & 30 & 0.041 \\
\hline 39 & Science subjects help development of my & 1.57 & 0.94 & 0.00 & -1.69 & -0.72 & -0.49 & 0.04 & 47.27 & 24 & 0.003 \\
\hline
\end{tabular}


Table 3

G G UM Item Parameter Estimates (D erived from M arginal M aximum Likelihood Estimation) for 47 Attitude Items Toward Science

\begin{tabular}{|c|c|c|c|c|c|c|c|c|c|c|c|}
\hline & Item & $\delta \mathrm{i}$ & $\alpha_{\mathrm{i}}$ & $\tau_{\mathrm{i} 1}$ & $\tau_{12}$ & $\tau_{i 3}$ & $\tau_{i 4}$ & SE & $\mathrm{G}^{2}$ & DF* & $\mathrm{P}$ \\
\hline & conceptual skills. & & & & & & & & & & \\
\hline 17 & $\begin{array}{l}\text { I need my friend's help in studying } \\
\text { science. }\end{array}$ & 1.68 & 0.70 & 0.00 & -2.79 & -1.77 & -0.40 & 0.11 & 39.39 & 30 & 0.005 \\
\hline 42 & $\begin{array}{l}\text { I think science subjects improve the quali- } \\
\text { ty of our lives. }\end{array}$ & 1.72 & 0.91 & 0.00 & -1.88 & -0.90 & -0.49 & 0.19 & 31.08 & 24 & 0.152 \\
\hline 15 & $\begin{array}{l}\text { I run my free time in practicing scientific } \\
\text { activities. }\end{array}$ & 1.84 & 1.02 & 0.00 & -1.82 & -1.27 & -0.46 & 0.09 & 39.27 & 24 & 0.026 \\
\hline 14 & $\begin{array}{l}\text { Learning science subjects helps me un- } \\
\text { derstand the universe better. }\end{array}$ & 2.05 & 1.19 & 0.00 & -2.28 & -1.20 & -0.64 & 0.28 & 11.86 & 18 & 0.854 \\
\hline 35 & $\begin{array}{l}\text { I feel studying science subjects, is not that } \\
\text { useful. }\end{array}$ & 2.10 & 1.15 & 0.00 & -1.86 & -1.20 & -0.49 & 0.18 & 15.02 & 18 & 0.660 \\
\hline 38 & Studying science subjects leads to facts. & 2.12 & 0.68 & 0.00 & -1.79 & -1.55 & -0.02 & 0.14 & 30.26 & 27 & 0.303 \\
\hline 11 & $\begin{array}{l}\text { Science knowledge is essential for under- } \\
\text { standing other subjects and phenomenon. }\end{array}$ & 2.34 & 1.01 & 0.00 & -1.79 & -1.18 & -0.66 & 0.24 & 19.77 & 18 & 0.006 \\
\hline 10 & $\begin{array}{l}\text { I like talking to my friends about science } \\
\text { subjects. }\end{array}$ & 3.00 & 1.08 & 0.00 & -2.58 & -1.80 & -1.25 & 0.28 & 35.10 & 18 & 0.090 \\
\hline 9 & $\begin{array}{l}\text { I would like to specialize in one of the } \\
\text { science subjects. }\end{array}$ & 3.05 & 0.74 & 0.00 & -1.80 & -1.72 & 0.17 & 0.29 & 25.27 & 15 & 0.046 \\
\hline 33 & $\begin{array}{l}\text { I wish to have more scientific activities in } \\
\text { our country. }\end{array}$ & 4.47 & 0.41 & 0.00 & -3.75 & -4.44 & -1.19 & 0.08 & 37.73 & 30 & 0.157 \\
\hline
\end{tabular}

* DF=HF, where $\mathrm{H}=$ number of fit groups out of 10 , where 10 groups were determined by the researchers as a hypothetical value the model adopts, and $C=4-1$, where 4 is the number of response scale used in the present study.

**significant at $\alpha=0.01$

Table 3 shows that the item parameters $\delta_{1}$ ranged from (-3.51 to 4.47), and $\mathrm{G}^{2}$ values indicate that 7 items misfit the model, with significant differences at $\alpha=0.01$ between the expected and observed scores. Then 40 items ( 20 negative, and 20 positive) retained in the final scale. Cronbach's $\alpha$ was .932 for the internal consistency of the final scale, and the test retest reliability coefficient was .875 .

G GUM Item Parameter Estimates (Derived From M arginal Maximum Likelihood Estimation) for $\mathbf{4 0}$ Items of Attitudes toward

\begin{tabular}{|c|c|c|c|c|c|c|c|c|c|c|c|}
\hline & Item & $\delta_{\mathrm{t}}$ & $\alpha_{l}$ & $\tau_{\mathrm{t} 1}$ & $\tau_{12}$ & $\tau_{13}$ & $\tau_{14}$ & SE & $\mathrm{G}^{2}$ & DF* & $P$ \\
\hline 43 & $\begin{array}{l}\text { Science subjects are not important in com- } \\
\text { parison with other subjects. }\end{array}$ & -2.5 & 0.71 & 0.00 & -2.69 & -1.67 & 0.33 & 0.54 & 26.41 & 24 & 0.33 \\
\hline 19 & $\begin{array}{l}\text { I feel uncomfortable during study of } \\
\text { science subjects. }\end{array}$ & -2.34 & 0.74 & 0.00 & -2.14 & -1.73 & 0.05 & 0.44 & 17.70 & 24 & 0.82 \\
\hline 18 & $\begin{array}{l}\text { I feel my desire toward science subjects } \\
\text { decreases by time. }\end{array}$ & -2.24 & 0.82 & 0.00 & -1.88 & -1.65 & 0.33 & 0.34 & 27.92 & 21 & 0.14 \\
\hline 41 & $\begin{array}{l}\text { I see that science subjects, present limited } \\
\text { information for a person. }\end{array}$ & -2.04 & 0.90 & 0.00 & -1.69 & -0.86 & 0.25 & 0.25 & 19.55 & 21 & 0.55 \\
\hline 35 & $\begin{array}{l}\text { I feel studying science subjects, is not that } \\
\text { useful. }\end{array}$ & -1.97 & 0.69 & 0.00 & -1.82 & -1.65 & -0.01 & 0.21 & 30.29 & 27 & 0.30 \\
\hline 40 & Science subjects are repulsive. & -1.90 & 1.40 & 0.00 & -2.14 & -1.11 & -0.43 & 0.15 & 15.1 & 15 & 0.45 \\
\hline 16 & I feel nervous in science lessons. & -1.85 & 1.51 & 0.00 & -1.90 & -1.16 & -0.04 & 0.14 & 10.24 & 12 & 0.60 \\
\hline 13 & $\begin{array}{l}\text { Public money spent on science could have } \\
\text { been used more wisely for other purposes. }\end{array}$ & -1.74 & 0.92 & 0.00 & -1.94 & -1.46 & -0.30 & 0.15 & 10.78 & 24 & 0.99 \\
\hline 12 & $\begin{array}{l}\text { Participation in scientific clubs is a waste of } \\
\text { time. }\end{array}$ & -1.60 & 1.05 & 0.00 & -2.20 & -1.45 & -0.46 & 0.12 & 20.59 & 21 & 0.48 \\
\hline 44 & $\begin{array}{l}\text { I feel studying science subjects is a waste of } \\
\text { time. }\end{array}$ & -1.53 & 0.81 & 0.00 & -1.36 & -1.20 & 0.46 & 0.14 & 34.93 & 24 & 0.07 \\
\hline 31 & I lose attention in science lessons. & -1.43 & 1.07 & 0.00 & -2.21 & -1.21 & -0.37 & 0.11 & 26.5 & 24 & 0.33 \\
\hline 30 & $\begin{array}{l}\text { I believe that science subjects are given } \\
\text { more attention than they deserve. }\end{array}$ & -1.24 & 0.93 & 0.00 & -1.53 & -1.18 & 0.12 & 0.10 & 22.53 & 24 & 0.55 \\
\hline 7 & $\begin{array}{l}\text { I dislike watching scientific programs on } \\
\text { T.V. }\end{array}$ & -1.17 & 0.98 & 0.00 & -2.29 & -1.56 & -0.28 & 0.10 & 11.47 & 24 & 0.99 \\
\hline 28 & $\begin{array}{l}\text { Disadvantages of science subjects dominate } \\
\text { its advantages. }\end{array}$ & -1.04 & 0.78 & 0.00 & -2.40 & -1.11 & -0.21 & 0.11 & 28.00 & 30 & 0.57 \\
\hline 6 & $\begin{array}{l}\text { I hate that my success in the future de- } \\
\text { pends on learning science subjects. }\end{array}$ & -0.87 & 0.73 & 0.00 & -1.83 & -1.48 & -0.11 & 0.09 & 26.68 & 30 & 0.64 \\
\hline 27 & $\begin{array}{l}\text { Science subjects are not important in the } \\
\text { evolution of human. }\end{array}$ & -0.85 & 0.85 & 0.00 & -1.80 & -0.99 & -0.09 & 0.08 & 20.99 & 27 & 0.79 \\
\hline 20 & I dislike a career as a scientist. & -0.78 & .66 & 0.00 & -1.36 & -0.76 & 0.23 & 0.09 & 31.88 & 30 & 0.37 \\
\hline 23 & Science subjects have nothing to do with & -0.60 & .83 & 0.00 & -1.97 & -1.05 & -0.20 & 0.07 & 27.61 & 30 & 0.59 \\
\hline
\end{tabular}


able 4

G GUM Item Parameter Estimates (D erived From M arginal M aximum Likelihood Estimation) for $\mathbf{4 0}$ Items of Attitudes toward Science

\begin{tabular}{|c|c|c|c|c|c|c|c|c|c|c|c|}
\hline & Item & $\delta_{\mathrm{l}}$ & $\alpha_{l}$ & $\tau_{11}$ & $\tau_{12}$ & $\tau_{13}$ & $\tau_{14}$ & SE & $\mathrm{G}^{2}$ & DF* & $\mathrm{P}$ \\
\hline 2 & Science subjects are boring. & -0.58 & 0.86 & 0.00 & -2.04 & -1.32 & -0.18 & 0.06 & 25.24 & 30 & 0.71 \\
\hline 1 & Science subjects are difficult to understand. & -0.49 & 1.15 & 0.00 & -2.03 & -1.19 & -0.15 & 0.05 & 14.90 & 24 & 0.92 \\
\hline 37 & $\begin{array}{l}\text { My studying of science subjects makes me } \\
\text { feel I'm doing significant thing. }\end{array}$ & 0.31 & 1.03 & 0.00 & -2.29 & -1.37 & -0.64 & 0.05 & 31.82 & 27 & 0.24 \\
\hline 9 & $\begin{array}{l}\text { I would like to specialize in one of the } \\
\text { science subjects. }\end{array}$ & 0.38 & 0.75 & 0.00 & -1.42 & -0.99 & 0.02 & 0.06 & 20.21 & 30 & 0.91 \\
\hline 15 & $\begin{array}{l}\text { I run my free time in practicing scientific } \\
\text { activities. }\end{array}$ & 0.57 & 0.70 & 0.00 & -1.60 & -1.15 & -0.47 & 0.06 & 17.53 & 30 & 0.97 \\
\hline 34 & I feel excited toward science subjects. & 0.68 & 0.86 & 0.00 & -2.04 & -1.49 & -0.54 & 0.06 & 21.63 & 30 & 0.87 \\
\hline 47 & $\begin{array}{l}\text { Science lessons will help prepare me for } \\
\text { major decisions in my future. }\end{array}$ & 0.88 & 1.02 & 0.00 & -1.82 & -1.03 & 0.02 & 0.07 & 30.62 & 27 & 0.29 \\
\hline 46 & $\begin{array}{l}\text { Interest in science subjects contribute to the } \\
\text { progress and advancement of society. }\end{array}$ & 1.00 & 0.93 & .00 & -2.03 & -.96 & -.37 & 0.07 & 16.1 & 27 & 0.95 \\
\hline 33 & $\begin{array}{l}\text { I wish to have more scientific activities in } \\
\text { our country. }\end{array}$ & 1.00 & 1.28 & 0.00 & -1.78 & -1.27 & -0.24 & 0.06 & 29.79 & 24 & 0.19 \\
\hline 38 & Studying science subjects leads to facts. & 1.11 & 0.60 & 0.00 & -1.87 & -1.44 & -0.39 & 0.12 & 26.71 & 30 & 0.64 \\
\hline 32 & $\begin{array}{l}\text { Science subjects provide me information } \\
\text { that is not known to the average person. }\end{array}$ & 1.12 & 1.01 & 0.00 & -2.20 & -1.26 & -0.42 & 0.08 & 14.03 & 24 & 0.95 \\
\hline 5 & I wait for the science classes eagerly. & 1.28 & 1.04 & 0.00 & -1.98 & -0.87 & -0.20 & 0.09 & 43.00 & 27 & 0.03 \\
\hline 45 & $\begin{array}{l}\text { I wish school subjects are limited to science } \\
\text { subjects. }\end{array}$ & 1.33 & 0.70 & 0.00 & -1.88 & -1.01 & -0.11 & 0.14 & 46.64 & 27 & 0.04 \\
\hline 29 & I enjoy in studying science subjects. & 1.36 & 0.71 & 0.00 & -1.60 & -1.83 & -0.10 & 0.13 & 29.84 & 30 & 0.47 \\
\hline 3 & $\begin{array}{l}\text { I like science subjects more than any other } \\
\text { subject. }\end{array}$ & 1.50 & 1.00 & 0.00 & -1.64 & -0.66 & -0.35 & 0.10 & 35.11 & 24 & 0.07 \\
\hline 25 & $\begin{array}{l}\text { I think that science subjects are the main } \\
\text { reason of technology development. }\end{array}$ & 1.69 & 0.71 & 0.00 & -2.82 & -1.79 & -0.31 & 0.20 & 46.94 & 30 & 0.03 \\
\hline 4 & $\begin{array}{l}\text { Science subjects are beneficial to every- } \\
\text { body. }\end{array}$ & 1.77 & 0.92 & 0.00 & -1.87 & -0.98 & -0.40 & 0.15 & 17.58 & 24 & 0.82 \\
\hline 14 & $\begin{array}{l}\text { Learning science subjects helps me under- } \\
\text { stand the universe better. }\end{array}$ & 1.81 & .39 & 0.00 & -.92 & -1.74 & 1.87 & 0.31 & 30.02 & 30 & 0.46 \\
\hline 24 & $\begin{array}{l}\text { I feel that studying science subjects helps } \\
\text { refining my character. }\end{array}$ & 1.89 & 1.09 & 0.00 & -1.83 & -1.32 & -0.43 & 0.15 & 17.83 & 18 & 0.47 \\
\hline 21 & $\begin{array}{l}\text { I gain from studying science subjects, accu- } \\
\text { racy in work. }\end{array}$ & 1.95 & 1.18 & 0.00 & -2.16 & -1.10 & -0.48 & 0.15 & 10.22 & 18 & 0.92 \\
\hline 10 & $\begin{array}{l}\text { I like talking to my friends about science } \\
\text { subjects. }\end{array}$ & 2.10 & 0.66 & 0.00 & -1.67 & -1.49 & 0.24 & 0.29 & 22.59 & 27 & 0.71 \\
\hline 42 & $\begin{array}{l}\text { I think science subjects improve the quality } \\
\text { of our lives. }\end{array}$ & 2.21 & 1.10 & 0.00 & -1.90 & -1.30 & -0.44 & 0.18 & 11.68 & 18 & 0.86 \\
\hline
\end{tabular}

* DF=HF, where $\mathbf{H}=$ number of fit groups out of 10, where $\mathbf{1 0}$ groups were determined by the researchers as a hypothetical value the model adopts, and $C=4-1$, where 4 is the number of response scale used in the present study.

After deleting misfit persons and items, the data were reanalyzed. Item parameters of the final scale were estimated using marginal maximum likelihood as shown in Table 4.

Table 4 shows GGUM item parameter estimates of the final scale, listed in order of increasing $\delta_{l}$, and corresponding to negative, neutral, and positive affective content. The values of $\delta$ ranged reasonably from -2.5 to 2.21 across items. $\mathrm{G}^{2}$ values indicated that all items of the final scale fit the model at $\alpha=0.01$.

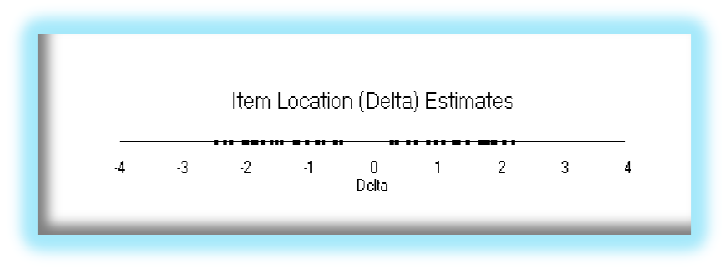

Fig. 3: Item Location (D elta) Estimates
Figure 3 shows the locations of items (dot line) and location of persons (solid line) on the attitude continuum, where positive items grouped on the right side of the attitude continuum, while the negative items grouped on the left side. The consistency between item content and item location supports the adequacy of the model.

Figure 3 indicates that from the person's location we can know the items that he agrees with, where the closer the location of the person to the location of the item, the greater the probability of agreement with the content of the item. Fit of GGUM appeared reasonable.

The likelihood ratio global $\chi^{2}$ was insignificant at $\alpha=0.1$, where $\chi^{2}=969.14$ with $P<.81$, which means that expected and observed responses are consistent, as shown in figure 4. 


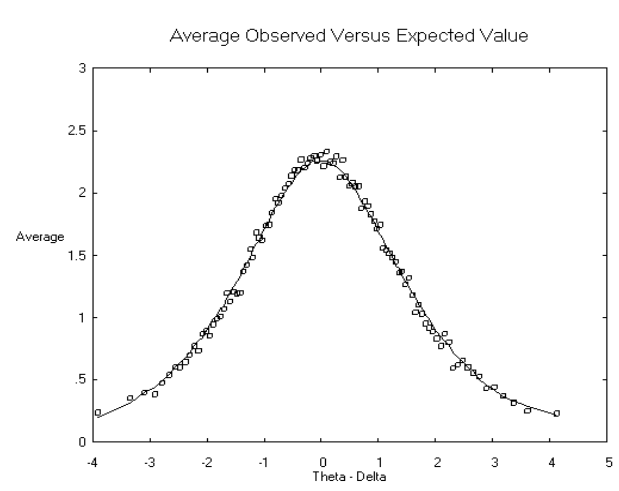

Fig. 4: A verage $O$ bserved Versus Expected $V$ alue

Figure 4 shows the close of the observed curve (squares) from the expected curve (solid line), yielded sample free item parameters within different levels of the attitude, which means the GGUM adequately fit the data. The mean of the $\hat{\theta}$ distribution and the standard deviation were $(0.0012,0.973)$ respectively with standard error of 0.04 which is close from normal distribution. Figure 5 shows the latent trait distribution.

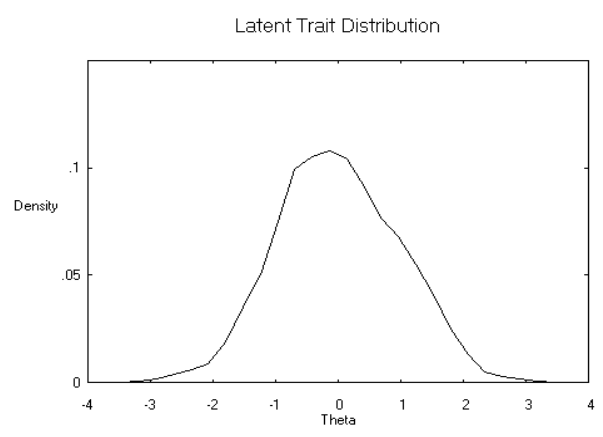

Fig. 5: Latent Trait D istribution

It is clear from figure 5 that the distribution doesn't differ from a normal distribution. Results showed that all item characteristic curves (ICC) were nonmonotonic, where the probability of choosing an item increases with decreasing distance between the locations of person and item.

All item characteristic curves yielded the test characteristic curve of the final scale as presented in figure 6 .

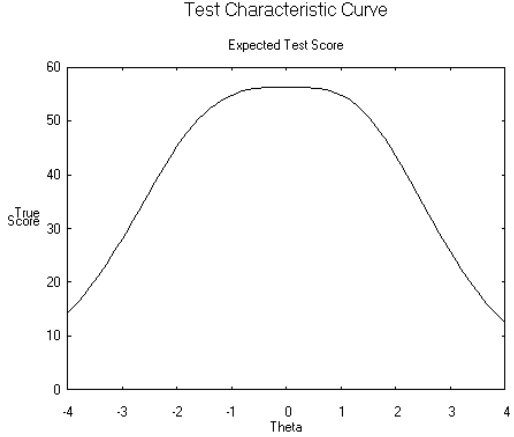

Fig. 6: Test Characteristic Curve

Figure 6 indicates the probability of estimating the expected true score at each level of ability $\left(\theta_{\mathrm{j}}\right)$.

\section{Test information function (TIF)}

Test information was estimated at each level of $\theta_{\mathrm{j}}$, Figure 7 presents the test information function curve of the final scale. It is clear from Figure 7 that the maximum value of information occurred at $\theta=0$, with information from persons whose attitudes occurred between $\theta=$ -2.5 and $\theta=2.5$ across continuum.

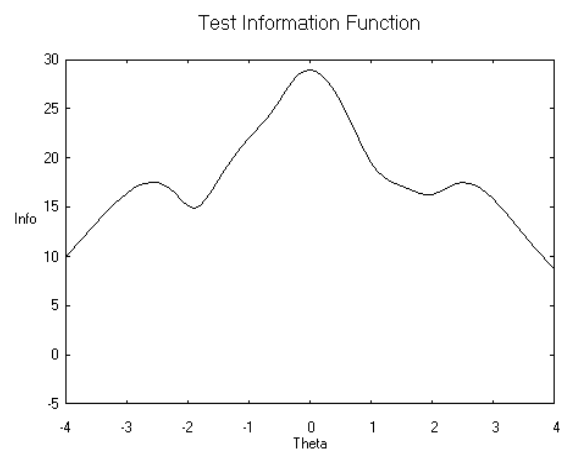

Fig. 7: Test Information Function

\section{DISCUSSION AND CONCLUSION}

The present study aimed at constructing an attitude scale toward school science using the general graded unfolding model (GGUM). The unidimensionality assumption of the GGUM was explored using a principal components analysis. The results verified the unidimensionality assumption of the GGUM held for the data used in the study, where the proportion of the eigenvalue of the first factor to the eigenvalue of the second factor was greater than 2 , and the first factor was dominant.

GGUM item parameters were estimated using marginal maximum likelihood. Results showed that 7 items exhibited a high degree of 
misfit. Therefore 40 items retained for the final form of the scale. GGUM was found to fit the data of the study, and the marginal maximum likelihood provided reasonably accurate estimates of parameters. This result was quite consistent with the results of most previous studies (e.g., Roberts \& Laughlin, 1996; Roberts, et al., 2001; Zampetakis; 2010).

The internal consistency was established by computing the Cronbach's alpha for the final form of the scale. Cronbach's alpha was 0.932, and the test retest reliability coefficient of the final scale was 0.875 . These results reflect acceptable levels of internal consistency and reliability.

The results indicated that the (GGUM) model fit the data, where the average expected and the average observed responses increased as the mean difference between person and item locations approached zero. Results also showed that all item characteristic curves implemented Single-Peaked, nonmonotonic probability functions. These findings were consistent with the findings of other previous studies (Roberts, 2001; Roberts et al., 2000; \& Roberts, Lin, \& Laughlin, 2001). The item elicited greater level of agreement as the distance between the person and the item on the attitude continuum decreased.

The results of the present study revealed no gap between the estimated locations of the items. This result, however was inconsistent with the result of Roberts \& Laughlin (1996). This could be due to the larger number of items in the present study. The findings also indicated the possibility of developing an item set spans al ong the attitude continuum.

The results also showed that (GGUM) is appropriate for agree-disagree data (Roberts, 1995; Roberts, Donoghue, \& Laughlin, 2000, Roberts and Laughlin, 1996). The model yielded desired information along the attitude continuum and from the persons with extreme attitudes, where parameter estimates and the test information function demonstrated that the scale can be used to measure the attitude accurately at lower to middle to higher levels of this trait. This result was inconsistent with the results of (Zampetakis, 2010; and Roberts, et al., 2001), and it could be due to the larger number of items of the present study.

Finally, the present study yielded sample free item parameters, and item invariant person parameters. This result agreed with previous studies (H ambleton, Swaminathan, \& Rogers, 1991; Hoijtink, 1990) in that if a parametric unfolding model is used, and adequately fits the data, then the item parameters will be sample free and the person parameters will be item invariant.

\section{REFEREN CES}

Andrich, D. (1988). The application of an unfolding model of the PIRT type to the measurement of attitudes. A pplied Psychological M easurement, 12 (1), 33- 51.

Andrich, D. (1993). A hyperbolic cosine latent trait model for unfolding dichotomous single-stimulus responses. A pplied Psychological M easurement, 17 (3), 253- 276.

Andrich, D. (1996). A general hyperbolic cosine latent trait model for unfolding polytomous responses: Reconciling Thurstone and Likert methodologies. British Journal of $M$ athematical and Statistical Psychology, 49, 347- 365.

Cheung. D. (2009). Students' attitudes toward chemistry lessons: The interaction effect between grade level and gender. Research in Science Education, 39 (1), 75-91.

Embretson, S.E. (1996). The new rules of measurement. Psychological Assessment, 8 (4), 341- 349.

George, R. (2006). A cross-domain analysis of change in students' attitudes toward science and attitudes about the utility of science. International Journal of Science E ducation, 28(6), 571-589.

Germann. P. J. (1988). Development of the attitude toward science in school assessment and its use to investigate the relationship between science achievement and attitude toward science in school. Journal of $R e$ search in Science Teaching, 25 (8), 689- 703.

Hambleton, R.K.; Swminathan, H. \& Rogers, H.J. (1991). Fundamentals of Item Response Theory. Thousand Oaks, CA: Sage Publication.

Hattie, J. (1984). An empirical study of various indices for determining unidimensionality. M ultivariate Behavioral Research, 19, 4978.

Hoigtink, H. (1990). A latent trait model for dichotomous choice data. Psychometrika, 55 (4), 641- 656. 
Hoijtink, H. (1991). The measurement of latent traits by proximity items. A pplied Psychological M easurement, 15 (2), 153- 169.

Koballa, T. \& Crawley, F. (1985). The influence of attitude on science teaching and learning. School Science and M athematics. 85 (3), 222- 232.

Laforgia, J. (1988). The affective domain related to science and its evaluation. Science Education, 72 (4), 407- 421.

Morse, L. W. \& Morse, D. T. (1995). The influence of problem- solving strategies and previous training on performance of convergent and divergent thinking. Journal of Instructional Psychology, 22(4), 341- 349.

Osborne, J., Simon, S., \& Collins, S. (2003). Attitudes towards science: A review of theliterature and its implications. International Journal of science Education, 25 (9), 10491079.

Prokop, P., Tuncer, G., \& Chuda, J. (2007). Slovakian students' attitudes toward biology. Eurasia Journal of $M$ athematics, Science and Technonogy Education, 3(4), 287- 295.

Roberts, J. S. (1995). Item response theory approaches to attitude measurement. DAI-B $56 / 12,7089$.

Roberts, J. S. (2001). Computer program exchange GGUM 2000: Estimation of parameters in the generalized graded unfolding model. Applied Psychological M easurement, 25 (1), 38.

Roberts, J. S. (2003). A n item fit statistic based on pseudocounts from the generalized graded unfolding model: A preliminary report. Paper Presented at the Annual Meeting of the American Educational Research Association. ERIC N o: Ed 476920.

Roberts, J. S. (2004). GGUM 2004 Technical Reference $M$ anual $V$ ersion 1.

Roberts, J. S., \& Laughlin, J. E. (1996). A unidimensional item response model for unfolding responses from a graded disagreeagree response scale. A pplied Psychological M easurement, 20 (3), 231- 255.

Roberts, J. S., Donoghue, J. R., \& Laughlin, J. E. (1999). Estimability of parameters in the generalized graded unfolding model. Paper presented at the Annual Meeting of the American Educational Research Association (Montreal, Quebec, Canada).
Roberts, J. S., Donoghue, J. R., \& Laughlin, J. E. (2000). A general item response theory model for unfolding unidimensional polytomouse responses. A pplied Psychological M easurement, 24(1), 3- 32.

Roberts, J. S., Lin, Y., \& Laughlin, J. E. (2001). Computerized adaptive testing with the generalized graded unfolding model. A pplied Psychological M easurement, 25 (2), 177196.

Roberts, J. S., Laughlin, J. E., \& Wedell, D. H. (1999). Validity issues in the Likert and Thurstone approaches to attitude measurement. Educational and Psychological M easurement, 59 (2), 211-233.

Salta, K, \& Tzougraki, C. (2004). Attitudes toward chemistry among 11 'th grade students in high schools in Greece. Science Education, 88 (4), 535- 547.

Schibeci, R. A., \& Riley, J. P. Jr. (1986). Influence of students' background and perceptions on science attitudes and achievement. Journal of Research in Science Teaching, 23 (3), 177- 187.

Siegel, M. A., \& Ranney, M. A. (2003). Developing the changes in attitude about the relevance of science (CARS) questionnaire and assessing tow high school science classess. Journal of Research in Science Teaching, 40 (8), 757- 775.

Simpson, R. D., \& Oliver, J. S. (1990). A summary of major influences on attitude toward and achievement in science among adolescent students. Science Education, 74 (1), 1-18.

Van Schuur, W. H., \& Kiers, H. A. L. (1994). Why factor analysis is often the incorrect model for analyzing bipolar concepts, and what model to use instead. A pplied Psychological M easurement, 18 (2), 97- 110.

Wang, W.C., \& Liu, C. W. (2011). Computerized classification testing under the generalized graded unfolding model. Educational and Psychological M easurement, 7 (1), $114-128$.

Zampetakis, L. A. (2010). Unfolding measurement of the creative personality. Journal of Creative Behavior, 44 (2), 105 - 123. 